\title{
Ataque al personal de la salud durante la pandemia de COVID-19 en Latinoamérica
}

\author{
Attacks on healthcare workers during the \\ COVID-19 pandemic in Latin America
}

\author{
*Foro Internacional de Medicina Interna (FIMI) \\ Pascual Rubén Valdés, luis Alberto Cámera, Mariano de la Serna • (Argentina) / Yazmin Abuabara-Turbay, \\ Virgil Carballo-Zárate, Helí Hernández-Ayazo, Rita Magola Sierra-Merlano, Aníbal Viera-Jaraba • (Colombia) / \\ Diana Rodriguez-Hurtado • (Perú) / Andrea Vaucher-Rivero • (Uruguay) / Felipe Melgar-Cuéllar, \\ Carlos Ibáñez-Guzmán, • (Bolivia) / Carlos Araya-Fonseca (Costa Rica) • Isis Betancourt-Torres • (Cuba) / \\ Rubén Montúfar-Guardado • (El Salvador) / Carlos Nitsch-Montiel • (Guatemala) • Claudia Regina Brav-Mejía, \\ Denise Alejandra Salgado-Guevara, Pamela Lizzeth Bustillo-Valeriano • (Honduras) / Alejandro Cárdenas-Cejudo, \\ Mauricio Sarmiento-Chavero • (México) / Nuvia Batista-Rujano • (Panamá) / María Cristina Jiménez • (Paraguay) \\ / Claudia Y. Arias-Burroughs (República Dominicana) / Maritza Durán-Castillo (Venezuela) / \\ Santiago Carrasco-Dueñas (Ecuador)
}

DOI: https://doi.org/10.36104/amc.2020.1975

¿Cómo vas a saber lo que es la adrenalina si nunca trabajaste en un código rojo?

¿Cómo vas a saber lo que es la precisión si nunca pusiste una vía que parecía imposible?

¿Cómo vas a saber lo que es paciencia si nunca te quedaste (por más que estabas apurado) a escuchar la historia que te contaba tu paciente?

¿Cómo vas a saber lo que es la tristeza si nunca viste llorando a un familiar despidiéndose de su ser querido?

¿Cómo vas a saber lo que es la angustia si nunca entraste a ver al paciente después de que su médico le dio el peor diagnóstico?

¿Cómo vas a saber lo que es aceptación si nunca viste a un familiar con los ojos llenos de lágrimas firmar el formulario no reanimación?

¿Cómo vas a saber lo que es el miedo si nunca viste la cara de un padre cuando entra en quirófano su hijo?

¿Cómo vas a saber lo que es el orgullo si nunca te abrazó y te agradeció un familiar por salvar una vida?

¿Cómo vas a saber lo que es felicidad si nunca viste la cara de los padres de un recién nacido que trajiste al mundo?

¿Cómo vas a saber lo que se extraña a tu familia en las fiestas si nunca te tocó una guardia en Navidad o fin de año?

¿Cómo vas a comprender mis emociones si nunca te has puesto mi uniforme?

¿Cómo te atreves a juzgar a un profesional de la salud sin conocer su historia?

De esta salimos todos juntos

Para todos aquellos que aún dudan de lo que está pasando o no lo toman en serio...

Orgullo de pertenecer... no son nuestras palabras, pero nos hacemos eco porque nos sentimos absolutamente identificados como muchos de ustedes.

Tomado del muro de Facebook de la Dra Alejandra Sánchez Cabezas, Presidente del Consejo de Salud Comunitaria de la Sociedad Argentina de Medicina (SAM) 
DOI: https://doi.org/10.36104/amc.2020.1975

\section{Resumen}

En la actualidad los profesionales de la salud son el recurso más valioso con el que cuenta cada país para combatir la enfermedad COVID-19. Las tasas de contagio intrahospitalario son altas y ligadas al acto de atención sanitaria. Las medidas de protección por parte de los empleadores son fundamentales para el cuidado de los que cuidan. La situación de pánico generada por el temor a contraer o transmitir la enfermedad, siendo primeros respondedores en la línea de combate ante la pandemia, ha sido amplificada por varios factores. Cuestiones como presión psicológica, carga laboral, mediatización, aspectos judiciales, desprotección, falta de descanso, nuevos roles, discriminación y agresiones son algunas de las situaciones a las que se los profesionales se deben enfrentar.

(Acta Med Colomb 2020; 45. DOI: https://doi.org/10.36104/amc.2020.1975).

Palabras clave: pandemia, COVID-19, discriminación, agresiones, personal de salud.

\section{Abstract}

Today, healthcare professionals are a country's most valuable resource for combating COVID-19. Hospital contagion rates are high and linked to the practice of health care. Employers' protective measures are essential in caring for the caregivers. The panic resulting from a fear of contracting or transmitting the disease, with first responders being at the front line of the battle against the pandemic, has been amplified by various factors. Issues such as psychological pressure, workload, media coverage, legal aspects, lack of protection, lack of rest, new roles, discrimination and assaults are some of the situations faced by these professionals. (Acta Med Colomb 2020; 45. DOI: https://doi.org/10.36104/amc.2020.1975).

Palabras clave: pandemic, COVID-19, discrimination, assaults, healthcare workers.

\section{*Foro Internacional de Medicina Interna (FIMI)}

Dr. Pascual Rubén Valdez: Doctorado en Medicina. Especialista en Clínica Médica/Medicina Interna, Medicina Crítica y Terapia Intensiva, Profesor de Medicina Interna en UBA y en UNLaM. Presidente del Foro Internacional de Medicina Interna (FIMI); Dr. Luis Alberto Cámera: Especialista en Clínica Médica/Medicina Interna, Jefe Sección de Geriatría Departamento de Medicina Interna, Hospital Italiano de Buenos Aires, Profesor del Instituto Universitario del Hospital Italiano; Dr. Mariano de la Serna: Médico Hospitalista Hospital Italiano La Plata, Especialista en Economía de la Salud, Presidente del Distrito La Plata de la Sociedad Argentina de Medicina (SAM). Buenos Aires (Argentina); Dra. Yazmín Abuabara-Turbay: Especialista en Medicina Interna, Docente Asociado Departamento Médico Facultad de Medicina, Universidad de Cartagena, Tesorera Asociación Colombiana de Medicina Interna; Dr. Virgil Carballo-Zárate: Especialista en Medicina Interna, Docente Asociado Departamento Médico Facultad de Medicina, Universidad de Cartagena, Hospitalista Hospital Naval y Clínica Madre Bernarda, Presidente Asociación Colombiana de Medicina Interna; Dr. Helí Hernández Ayazo: Especialista en Clínica Médica/ Medicina Interna, $\mathrm{PhD}$ en Ciencias de la Educación-Historia de la Medicina, Profesor Titular de Medicina Universidad de Cartagena, Internista de consulta Hospital Universitario del Caribe; Dra. Rita Magola Sierra-Merlano: Especialista en Medicina Interna y Reumatología, Docente Asociado Departamento Médico, Facultad de Medicina, Universidad de Cartagena; Dr. Aníbal Viera-Jaraba: Especialista en Medicina Interna y Cuidado Intensivo. Unidad de Cuidado Intensivo, Clínica Blas de Lezo. Cartagena (Colombia); Dra. Diana Rodríguez-Hurtado: MsC Epidemiología Clínica, Especialista en Medicina Interna y Geriatría, Profesora Principal Universidad Privada Cayetano Heredia (Perú); Dra. Andrea Vaucher-Rivero: Especialista en Medicina Interna, Profesora Adjunta de Clínica Médica Hospital Maciel, Facultad de Medicina, Presidente Sociedad de Medicina Interna del Uruguay (Uruguay); Dr. Felipe MelgarCuéllar: Especialista en Clínica Médica/Medicina Interna, Geriatría y Gerontología, Médico Geriatra de Planta Clínica Foianini, Secretario FIMI; Dr. Carlos Ibáñez-Guzmán: Especialista en Medicina Interna, Medicina Crítica y Terapia Intensiva, Profesor Emérito de Medicina Universidad Mayor de San Andrés, Presidente Electo Sociedad Latinoamericana de Medicina Interna (Bolivia); Dr. Carlos Araya-Fonseca: Especialista en Medicina Interna, Profesor Asociado Universidad de Costa Rica (Costa Rica); Dra. Isis Betancourt-Torres: Especialista de Medicina Interna, Profesora Auxiliar de Medicina Interna, Máster en Aterosclerosis, Secretaria Sociedad Cubana de Medicina Interna (Cuba); Dr. Rubén Montúfar-Guardado: Especialista en Medicina Interna y Reumatología, Profesor Universidad Evangélica de El Salvador, Presidente Asociación de Medicina Interna de El Salvador. (El Salvador); Dr. Carlos Nitsch-Montiel: Jefe departamento de Medicina Interna Hospital Herrera LLerandi, Profesor de Medicina Interna, Universidad Francisco Marroquín (Guatemala); Dra. Claudia Regina Bravo-Mejía: Especialista en Medicina Interna, Medical Center/Hospital María Médico, Panel Embajada Americana en Honduras (Honduras); Dras. Denise Alejandra Salgado- Guevara y Pamela Lizzeth Bustillo-Valeriano: Doctoras en Medicina y Cirugía, Asistentes de Médico Panel en Clínica Atención Integral Bravo y de Clínicos triaje COVID Honduras Medical Center (Honduras); Dr. Alejandro Cárdenas-Cejudo: Doctor en Medicina, Especialista en Medicina Interna, Magíster en Administración de Instituciones de Salud; Dr. Mauricio Sarmiento-Chavero: Médico Cirujano, Especialista en Medicina Interna, Licenciatura en Derecho México; Dra. Nuvia Batista-Rujano: Especialista en Medicina Interna, Presidente Sociedad Panameña de Medicina Interna (Panamá); Dra. María Cristina Jiménez: Especialista en Medicina Interna y Nutrición Clínica, Profesor Titular Facultad de Medicina, Universidad Nacional de Asunción (Paraguay); Dra. Claudia Y. Arias-Burroughs: Tesorera Sociedad de Medicina Interna de la República Dominicana, Secretario General Asociación Centroamericana y del Caribe de Medicina Interna, Coordinadora para Centroamérica y el Caribe FIMI (República Dominicana); Dra. Maritza Durán Castillo: Especialista en Medicina Interna (Venezuela); Dr. Santiago Carrasco-Dueñas: Especialista de Medicina Interna. Docente de Pregrado Facultad de Medicina, Jefe de Medicina Interna Hospital Club de Leones Quito Central. Quito (Ecuador).

Correspondencia. Dra. Yazmín Cecilia Abuabara Turbay. Cartagena (Colombia).

E-mail: yatur20@hotmail.com

Recibido: 18/VII/2020 Aceptado: 31/VII/2020 
El brote del nuevo beta-coronavirus SARS-CoV ha sido -hasta el 21 de junio de 2020 - confirmado en 182 países y múltiples zonas territoriales, afectando a nivel mundial a aproximadamente ocho millones setecientos ocho mil ocho personas, de las cuales $5.3 \%$ han fallecido (1). La situación de emergencia de allí originada se convierte, sin lugar a dudas, en la mayor dificultad afrontada por el ser humano en el siglo XXI, y ha irrumpido en todos los aspectos de la cotidianidad; con inmensurables consecuencias a nivel sociocultural, político, económico, y por supuesto, con un impacto directo en la salud de los pacientes que desarrollan formas moderadas a severas de la enfermedad. Sin embargo, también ha generado un impacto indirecto en otros grupos poblacionales afectados colateralmente por la pandemia, como el personal de salud, quienes han resultado afectados por el contagio durante la atención de pacientes en los hospitales, pero también han resultado víctimas de hechos de discriminación, amenazas y agresiones físicas y psicológicas, dentro y fuera de los hospitales.

\section{Sobre las vidas en peligro dentro de los hospitales}

En la actualidad los profesionales de la salud son el recurso más valioso con el que cuenta cada país para combatir la enfermedad y debería ser un principio universal que estos recibieran el equipo de bioseguridad necesario para reducir el riesgo de contagio durante la atención de pacientes infectados por coronavirus (2). Esto es de máxima importancia teniendo en cuenta que, mientras la estrategia principal en todo el mundo ha sido orientar a la población a permanecer dentro de casa, el personal de salud se preparó para lo contrario, es decir, a desplazarse hasta centros asistenciales para brindar atención a pacientes portadores de un virus con altísima capacidad de transmisión (3).

A través de la prensa internacional pudo conocerse el caso de contagio -y posterior fallecimiento- del Dr. Chaolin Huang, uno de los primeros en reportar las manifestaciones encontradas en pacientes con la enfermedad por coronavirus (posteriormente denominada COVID-19). También fue descrita la infección del Dr. Wenliang Li, quien alertó sobre la emergencia del brote y posteriormente fue reprendido por la policía local, y la del Dr. Zhiming Liu, presidente del Hospital Wuchang de Wuhang, provincia de Hubei, región en donde se presume que emergió el brote $(4,5)$. De allí en adelante se ha podido corroborar que, producto de la exposición al virus, las tasas de contagio intrahospitalario han sido altas y ligadas al acto de atención sanitaria.

En China, al menos 3300 trabajadores del área de la salud han resultado afectados (3). En Italia, cerca de 5000 trabajadores del área de la salud infectados, y en España, más de 3000 trabajadores. En Colombia (6), el último reporte del Instituto Nacional de Salud (INS) demuestra que hay al menos 1547 profesionales afectados con la enfermedad, lo que corresponde a una proporción de $2.4 \%$ de todos los casos confirmados en el país. De los afectados, $32 \%$ son auxiliares de enfermería, $19 \%$ son médicos y $12.9 \%$ son enfermeras profesionales. Llamativamente $88 \%$ de los casos confirmados son sintomáticos, lo cual puede indicar un gran número de asintomáticos subregistrados o no testeados. Hasta la fecha, tres centros hospitalarios han tenido que ser cerrados debido a situación de transmisión masiva a personal de salud y administrativo dentro de dichos centros (7-9).

Por otra parte, en Cuba, hasta finales de abril se había registrado de acuerdo al reporte del Ministro de Salud una tasa de contagios del personal de salud de $7.7 \%$, dado por 92 trabajadores del sector, entre ellos 47 médicos. De 300 sanitarios confirmados con la COVID-19 hasta junio, no se registraba ningún fallecido. Así mismo en Panamá, se contabilizaban a principios de junio 440 casos en el personal de salud, y la Ministra de Salud de este país ha expresado en una entrevista que $17.5 \%$ de los médicos del Ministerio de Salud han adquirido la enfermedad.

Tabla 1. Casos en Latinoamérica al 18 de julio de 2020. (https://covid19info.live/)

\begin{tabular}{|c|c|c|c|c|}
\hline País & $\begin{array}{c}\text { Total } \\
\text { de casos }\end{array}$ & $\begin{array}{c}\text { Recuperados } \\
(\%)\end{array}$ & $\begin{array}{c}\text { Fallecidos } \\
(\%)\end{array}$ & $\begin{array}{c}\text { Siguen } \\
\text { cursando } \\
(\%)\end{array}$ \\
\hline Argentina & 122524 & 42.9 & 1.8 & 55.3 \\
\hline Bolivia & 58138 & 31.3 & 3.6 & 65.1 \\
\hline Brasil & 2075246 & 23.8 & 1.9 & 71.4 \\
\hline Chile & 328846 & 91.1 & 2.6 & 6.4 \\
\hline Colombia & 190700 & 45 & 3.4 & 51.6 \\
\hline Costa Rica & 10551 & 27.5 & 0.5 & 72 \\
\hline Cuba & 2445 & 94.2 & 3.6 & 2.2 \\
\hline Ecuador & 73382 & 43.3 & 7.2 & 49.5 \\
\hline El Salvador & 11508 & 57 & 2.8 & 40.2 \\
\hline Guatemala & 38042 & 61.4 & 3.8 & 34.8 \\
\hline Honduras & 32793 & 11.2 & 2.7 & 86.1 \\
\hline México & 338913 & 45.4 & 11.5 & 8.5 \\
\hline Panamá & 52261 & 52.6 & 2 & 45.3 \\
\hline Paraguay & 3629 & 45.3 & 0.8 & 53.9 \\
\hline Perú & 349500 & 68.1 & 3.7 & 28.2 \\
\hline $\begin{array}{l}\text { República } \\
\text { Dominicana }\end{array}$ & 51519 & 47.8 & 1.9 & 50.4 \\
\hline Uruguay & 1044 & 88.2 & 3.2 & 8.6 \\
\hline Venezuela & 11483 & 34.6 & 1 & 64.5 \\
\hline
\end{tabular}


El Perú, al 26 de junio del 2020 ocupa el sexto puesto en el mundo de casos infectados por COVID-19: con 268602 infectados, 8761 fallecidos y 156074 recuperados.

Y solo superados en Latinoamérica por Brasil que ocupa el segundo puesto a nivel mundial con 1233147 infectados, 55054 fallecidos y 673729 recuperados. En la Tabla 1 se observan las cifras en Latinoamérica al 18 de julio de 2020.

El Colegio Médico del Perú, al 26 de junio del 2020, reporta 1850 médicos infectados, de los cuales 46 están en unidades de cuidados intensivos y 12 de ellos muy graves, hasta el momento han fallecido 65 médicos en el Perú (19).

En Argentina, según datos del Ministerio de Salud de la Nación, el total acumulado de casos confirmados de COVID-19 en trabajadores de salud al 13 de julio de 2020, fue 7979 (sin antecedente de viaje) y representó $7.73 \%$ del total de los casos confirmados en el país. El $39.6 \%$ de casos acumulados presentó al menos un factor de riesgo. El número acumulado de fallecidos trabajadores de la salud es de 26 casos y representa $1.37 \%$ de todas las muertes por COVID-19. La letalidad en trabajadores de la salud es $0.33 \%$.

A nivel de instituciones sanitarias tres grandes factores han influido sobre la predisposición del personal de salud a contraer la enfermedad.

Primero, que el personal de las salas de emergencia no estaba entrenado frente a un virus nuevo, sobre el cual no se tenía experiencia y con muchos aspectos que se han venido a descubrir durante el transcurrir de la epidemia, lo que ha generado que los protocolos de atención cambien frecuentemente, predisponiendo a error y confusión. Ya en 2018, un estudio americano demostró que los profesionales de salud de áreas de emergencias a menudo carecen del conocimiento especializado para afrontar amenazas por enfermedades de tipo infectocontagiosas (11).

Segundo, que la enfermedad puede manifestarse con síntomas leves, síntomas atípicos o comportarse incluso de manera asintomática, por lo cual los agentes en salud pueden haberse expuesto a pacientes infectados que lucían sanos o consultaban por otros motivos, generando una falsa sensación de seguridad. Además en Latinoamérica, las salas de consulta externa y las áreas de espera en urgencias suelen estar permanentemente congestionadas y presentan tiempos de espera considerables, lo cual contribuye a la dispersión de la enfermedad. Peor aún la infección por coronavirus viene a concordar con el pico epidemiológico del dengue y la fiebre amarilla, así como con otras enfermedades contagiosas prevalentes en nuestro medio como el VIH y la tuberculosis, dificultando la concentración de los recursos, y comprometiendo la posibilidad de llevar a cabo los planes de contingencia necesarios para cumplir los protocolos de bioseguridad $(12,13)$.

Tercero, que por la alta transmisibilidad del virus, se requiere de un equipamiento de bioseguridad el cual es costoso, incómodo, y que debe ser eliminado tras su uso. El hecho que sea costoso implica que países con recursos limitados tendrán dificultad para su adquisición. Que sea incómodo implica un aumento en las tasas de desgaste físico del personal de salud y amerita de un tiempo para su correcta colocación, lo cual puede retrasar procesos de atención o realización de procedimientos. Que deba ser retirado y eliminado tras su uso indica que se requerirán múltiples trajes para la atención de pacientes por lo cual las instituciones sanitarias tratarán de decantar al máximo su uso, obligando incluso a la reutilización o al reciclaje de elementos que por seguridad deberían ser desechados. De hecho, se ha reportado que en algunos centros, conforme avanzó la epidemia, pudo observarse una reducción en la calidad de los materiales de los elementos de bioseguridad.

Finalmente, debe recordarse que todo lo anterior aplica no solamente para el equipo de protección personal de los médicos, sino también para los enfermeros y auxiliares de enfermería, para los terapistas respiratorios, para los técnicos de radiología y laboratorio clínico, personal paramédico, personal de limpieza, personal de alimentación, e incluye también el personal de transporte y manejo de muestras, todos los cuales requieren de equipos de protección.

Conforme avance la pandemia, se espera que ocurra un desabastecimiento progresivo de los equipos de bioseguridad, seguido de una guerra comercial competitiva por la adquisición y aseguramiento de dispositivos médicos que pondrá en desventaja a países con menores recursos.

En caso de no disponer de las herramientas de protección, es posible que el personal de salud decida limitar o evadir la atención de pacientes para evitar la exposición y contaminación sin la protección necesaria. Bajo este principio, se han reportado a través de redes sociales y noticias televisivas las renuncias de personal de salud (médicos, enfermeras, terapistas respiratorias) quienes han suspendido actividades al no recibir los equipos de bioseguridad por parte de sus centros hospitalarios $(14,15)$. Infortunadamente, fue también reportado que en algunas instituciones, los profesionales de salud que lideraron las solicitudes de garantías de equipos de seguridad o quienes pidieron ser testeados tras exposición a pacientes con la enfermedad fueron despedidos de sus lugares de trabajo (16).

La importancia de proveer equipos de protección personal apropiados al talento en salud ha sido expresada con vehemencia a través de pronunciamientos individuales, de sociedades científicas y de colectivos relacionados con el sector salud (17). Bajo la estructura de seguridad social en Colombia, se generó una polémica respecto a quien le correspondía la obligación de dotar al equipo de salud, si a las instituciones prestadoras de salud (ej. hospitales o centros hospitalarios), o si la responsabilidad recaía en las asegurados de riesgos laborales. La falta de legislación y supervisión por parte del gobierno, quien tampoco asumió la función de dotación, hizo que dichas partes fallaran en cumplir el abastecimiento necesario y se generaran vacíos legales en el proceso. En muchos casos, el personal de salud tuvo que recurrir a adquisiciones propias o a donaciones de terceros para abastecerse de equipos desechables. 
En Ecuador, la Federación Médica denunció la grave falta de equipos, y también la caducidad de otros, por ejemplo tomógrafos que tienen más de 10 años de funcionamiento y que han cumplido su vida útil que ya no representan una ayuda diagnóstica. Además, denunció casos de desabastecimientos de medicamentos esenciales para cirugías y terapia intensiva y falta de insumos básicos, mala calidad de mascarillas N95, la falta de prendas y protección en los hospitales del país, para todo el personal de salud y que por este problema muchos trabajadores de la salud han sufrido contagios (18).

\section{Sobre el ataque psicológico}

La situación de pánico generada por el temor a contraer o transmitir la enfermedad, siendo primeros respondedores en la línea de combate ante la pandemia, ha sido amplificada por varios factores. Por una parte, tiene que ver con el desconocimiento sobre una enfermedad viral nueva, de comportamiento errático y de la cual no hay a la fecha estrategias terapéuticas comprobadas. Por otra parte, tiene que ver con la incertidumbre generada por el cese indefinido del comercio y con la duración real de las medidas de cuarentena. Finalmente, el bombardeo permanente con escenas de angustia a través de medios de difusión y redes sociales, en algunos casos con propagación de informaciones imprecisas, han tenido un impacto negativo en un personal de salud ya frustrado y agotado. Esta situación de incertidumbre también se ve reflejada en el personal de salud que labora en urgencias por el impacto psicológico derivado de:

- La carga laboral que representa la atención de pacientes críticos con COVID-19, quienes con frecuencia desarrollan cuadros de insuficiencia respiratoria de manera muy rápida por lo cual requieren una revaloración frecuente y monitoreo constante bajo pesados equipos de protección y meticulosos protocolos de bioseguridad, lo cual genera rápido desgaste del personal.

- La posibilidad de contraer la infección y/o de transmitirla a seres queridos, especialmente en lugares con irregular disponibilidad de equipos de protección necesarios para afrontar su cuidado. Y a su vez, con la angustia del personal de salud que es responsable de otras personas (Ej. madres cabeza de hogar, hijos únicos), respecto a quien respondería por sus seres queridos en caso de sucumbir ante la enfermedad (19).

- La carga económica que resultaría de períodos de inactividad por tenerse que dar de baja en caso de contraer la enfermedad -o en su defecto por cuarentenas preventivas tras exposición al virus- las cuales en algunos países como Colombia no fueron debidamente aclaradas en el marco legal, dejando al profesional de salud sin respaldo jurídico y a las aseguradoras de salud o de riesgos laborales sin la obligatoriedad de responder por pago de incapacidades. Aunque debe aclararse que en otros países más afortunados, como Costa Rica, el ministerio de salud reguló la administración de incapacidades pagas mientras profesionales cumplían aislamiento.
- La alta carga de pacientes fallecidos, sobre todo en zonas epicentro como Bergamo, Madrid y Nueva York, en donde los centros de atención se vieron rápidamente sobresaturados generando sentimientos de angustia ante la magnitud de la situación, o de alto impacto emocional al tener que tomar decisiones de alto valor ético sobre vidas humanas bajo condiciones extremas. Esto incluye la carga derivada de la responsabilidad de proveer atención médica a pacientes muy complicados, con recursos incompletos, insuficientes o inadecuados (2). Finalmente incluye el duelo e impacto moral del equipo en salud a cargo de colegas, amigos, docentes o maestros que se infectan o fallecen ante la enfermedad (21).

Es importante señalar que aunque el personal de salud, especialmente de urgencias, está orientado para afrontar con temple situaciones de alto riesgo, usualmente no reciben estrategias de entrenamiento en salud mental por parte de sus hospitales. Incluso, miembros experimentados del personal de salud, asiduos a la tarea de informar malas noticias, pueden haberse visto superados ante el panorama de tener que notificar fallecimientos día tras día durante los picos de la pandemia, especialmente si esto se acompañó de sentimientos de impotencia o de culpa. En Italia fueron descritos al menos dos casos de suicidio de enfermeras y es posible que esto pueda ocurrir en otros lugares (22). Es necesario que se tomen medidas para promover la consejería al personal de salud en esta situación tan exigente, muy especialmente si se evidencian signos de desgaste, ansiedad o depresión, con el fin de minimizar el riesgo de desarrollar morbilidad psiquiátrica. En China por ejemplo, se tomaron algunas medidas específicas para paliar las dificultades descritas. Los centros hospitalarios recurrieron a garantizar salas de descanso en donde el cuerpo médico pudiera reposar, conceder la alimentación y los elementos del diario vivir, brindar herramientas de relajación, mayor esquema de seguridad frente aquellos pacientes involuntarios a la cooperación y aseguramiento de equipo de protección y bioseguridad, lo cual representa quizás la mayor preocupación del personal en servicio y de sus familiares en casa (23). De igual manera, otras instituciones incluyendo la OMS han publicado guías y recomendaciones con estrategias para proteger la salud mental de los profesionales (24).

En resultados preliminares expuestos por el equipo de investigación Salud de la Mujer, de la Universidad de Cartagena (Colombia), sobre el "estrés laboral y miedo al COVID-19 en médicos generales" se describió que, de 531 médicos encuestados, $84 \%$ reportaron tener temor ante la COVID-19. El 75\% de los encuestados respondió sentirse incómodo cuando pensaba en la pandemia, el $68 \%$ se siente nervioso cuando lee o escucha noticias relacionadas con la enfermedad, el $55 \%$ siente palpitaciones cuando piensa en el virus, y el 54\% no puede dormir por las mismas razones. El 38\% de los sondeados informó haber creído presentar síntomas similares a los padecimientos provocados por el 
virus. Además, el estudio encontró que las médicas (género femenino) reportaron tres veces más ansiedad que los hombres encuestados $(25,26)$.

Para terminar, debe destacarse también la presión psicológica que pueden haber ejercido las autoridades para evitar que los médicos o personal de salud expresaran sus preocupaciones a la comunidad, so pena de incurrir en sanciones disciplinarias o perder sus empleos. En Venezuela, se han reportado casos de médicos y enfermeros sancionados por los entes gubernamentales al haber denunciado las crisis hospitalarias (Anexo 1).

\section{Sobre la discriminación al personal de salud}

Llamativamente, otra faceta de este ataque psicológico durante la pandemia se ha evidenciado en cierta forma de discriminación, demostrado por el rechazo de miembros de la población general a mantener contacto con personal de salud por fuera del hospital, ante la sospecha de recibir de ellos la transmisión del virus; y que gradualmente se transformó en arremetidas más directas como la prohibición de la entrada de personal de la salud a supermercados y tiendas de abastecimiento, a evitar que usaran ascensores o áreas comunes en edificios y a que a profesionales de salud se les pidiera abandonar sus apartamentos. En Bogotá, se reportó el caso de un profesional de salud a quien mediante un grafiti se le amenazó de muerte a salir de la copropiedad, a riesgo de asesinar a su esposa e hijos (27). En ciudades como Nueva York, el bombardeo psicológico orientado a representar al personal de salud como potencial transmisor del virus obligó a que los mismos médicos y enfermeras decidieran dormir en sus vehículos y no regresar a sus hogares. Esta actitud persecutoria y discriminatoria contrastó altamente con los aplausos y ovaciones promulgados por la comunidad por pocos minutos en señal de apoyo al personal de salud.

Otra forma de discriminación fue evidenciada en el rechazo de los medios de transporte a trasladar a personal de medicina o enfermería vestidos con scrubs o piyamas quirúrgicas hacia los hospitales. Aunque el personal de salud prontamente aclaró que una vez dentro de las instituciones hospitalarias la ropa de calle se cambiaba por vestimenta hospitalaria, la población mantuvo su rechazo lo cual obligó a que en algunas ciudades las autoridades dispusieran de vehículos de traslado o rutas exclusivas para asegurar la movilidad de los trabajadores de la salud (28-29). Las instituciones sanitarias a su vez solicitaron a su staff no movilizarse con este tipo de vestimenta para evitar confrontaciones; sin embargo, esto condujo a que con alguna frecuencia los profesionales de salud vestidos de civil fueran multados por las autoridades, creyendo que se trataban de personas incumpliendo la cuarentena obligatoria.

En Argentina, el número de consultas al Instituto Nacional Contra la Discriminación, la Xenofobia y el Racismo (INADI) entre marzo y mayo de 2020 aumentaron considerablemente. De 718 consultas, 208 refieren específicamente a situaciones relativas a el COVID-19 en tanto enfermedad, ya sea por casos de discriminación hacia pacientes, agresiones y maltratos a personas expuestas, así como también a declaraciones estigmatizantes hacia distintos colectivos como la comunidad china y migrantes de varias nacionalidades, entre otros. En promedio, cuatro de cada 10 consultas tuvo que ver con la pandemia y/o el aislamiento, mientras que uno de cada 10 tuvo que ver puntualmente con discriminación por COVID-19. Predominantemente, las situaciones de discriminación ocurrieron más en mujeres (57\%) que en hombres (41\%). El barrio y la vivienda han sido el escenario más referido (71) en las 208 consultas que denuncian discriminación relativa a la COVID-19, y le siguen las redes sociales, donde se postean muchos comentarios discriminatorios, despectivos y violentos, a menudo alimentados por la difusión de las "fake news" o noticias falsas, que no sólo desinforman, sino que también generan miedos, ansiedades y opiniones basadas en datos y hechos poco veraces. Los ámbitos laboral y de la administración pública cuentan con 20 y 17 consultas, respectivamente, mientras que 13 de estas 208 hacen referencia a prestadores y centros de salud.

En Colombia, el presidente Iván Duque ha rechazado los actos de discriminación y ataque al personal médico, y el Defensor del Pueblo ha habilitado líneas anónimas para que puedan denunciarse hechos, amenazas u hostigamientos de los cuales puedan ser objeto (30). El Código Penal Colombiano (Artículo $134 \mathrm{~A}-\mathrm{C}$ ) expresa que las personas que incurran en actos de discriminación puede ser sancionados con penas de prisión de 12-36 meses y multas de 10-15 salarios mínimos legales mensuales vigentes, con riesgo de aumentar de una tercera parte a la mitad cuando la conducta se ejecute en espacio público, establecimiento público o lugar abierto al público. Aun así -tipificado bajo la ley-pudo rescatarse de la prensa nacional al menos 20 casos de agresión en diferentes ciudades de Colombia, de las cuales al menos ocho casos correspondieron a agresiones contra mujeres (enfermeras, auxiliares de enfermería, trabajadora social, tecnóloga de atención hospitalaria) y prácticamente todas obedecieron a situaciones de discriminación, especialmente en viviendas y supermercados. Tres médicos han sido amenazados de muerte, y sin embargo, hasta la fecha no se ha registrado ninguna persona penalizada por los actos mencionados.

Cuando se recopilan datos informativos publicados en la prensa en Latinoamérica, puede observarse que los casos de discriminación o violencia contra el personal de salud han ocurrido en muchos países además de Colombia, registrando al menos 111 casos repartidos así: México: 40, Colombia: 20, Argentina: 10, Venezuela: 9, Paraguay: 8, Honduras: 4, Panamá: 4, Perú: 2, Costa Rica: 1 y El Salvador: 1 (Anexo 1). El $45 \%$ de los casos de discriminación o violencia han ocurrido en mujeres mientras que $28 \%$ han ocurrido en hombres. El $40 \%$ de los casos de discriminación o violencia ocurren contra médicos, $40 \%$ contra enfermeras y auxiliares de enfermería (31) y $11 \%$ ocurren contra varios miembros del equipo de salud de manera simultánea. 
El $27 \%$ de los casos se dan en los centros asistenciales y otro $25 \%$ de los casos han ocurrido en las viviendas y edificios de los afectados, $19 \%$ de los casos han ocurrido en espacios públicos, $12 \%$ en medios de transporte público, $5 \%$ han ocurrido en establecimientos comerciales como restaurantes, supermercados y bancos, $4 \%$ de los casos han sido a través de redes sociales, aunque quizás el ciberacoso y los mensajes difamatorios por este medio son mucho más frecuentes pero casi nunca denunciados.

Respecto a las principales formas de violencia, tenemos que $31 \%$ de las noticias encontradas corresponden a formas varias de discriminación. En 21\% de los casos la violencia ocurrió por agresiones físicas, en $7 \%$ de los casos fue verbal, y en $13 \%$ de los casos las agresiones fueron mixtas. En $9 \%$ de los casos se dieron por abusos policiales o persecuciones a personal de la salud. En $11 \%$ de los casos ocurrieron amenazas a los personales de la salud.

La mayoría de casos de discriminación y agresión a personal de salud parece ocurrir en México, en donde la actual pandemia ha mostrado un aumento de la violencia. Personas que quieren quemar un hospital, que le arrojan café caliente o cloro a los médicos y enfermeras. Debemos de reconocer que con la pandemia no inició la violencia en contra de los profesionales de la salud, simplemente la amplificó, la hizo más visible, más cruda y despiadada. De acuerdo al derecho civil mexicano, existen cierto tipo de obligaciones que nacen de los actos ilícitos. En el artículo 1910 del Código Civil del Distrito Federal se establece que el que obrando ilícitamente o en contra de las buenas costumbres cause un daño está obligado a reparar el daño que causó. Por lo tanto, si se le causa daño a algún miembro de la comunidad médica, el que lo causó estaría obligado penal y civilmente a reparar dicho daño. El daño que se causa puede ser patrimonial, es decir, que tenga que ver con una pérdida económica, o también puede ser extra-patrimonial que principalmente abarca el daño moral. Debemos trabajar arduamente en mejorar la protección legal de los profesionales de la salud, pero debemos reconocer que principalmente tenemos la obligación de generar la voluntad en las autoridades para hacer que las leyes se cumplan. Se necesita un documento que englobe con energía el sentir de la comunidad médica y personal de salud de frente a la realidad social del contexto, la aplastante anarquía generada por la impunidad, la falta de acciones legales y los argumentos para empujar en todos los congresos y cámaras locales, para que cuanto antes se proceda a legislar y hacer cumplir la ley de manera ejemplar, antes de que la desgracia pase de ser una anécdota a formar parte de un acto cotidiano, esto es imperativo.

En Bolivia, mediante encuesta realizada sobre agresiones al personal de la salud, se encuentra que de 184 respuestas, $77.2 \%$ respondió afirmativamente haber sufrido algún tipo de agresión, principalmente en mujeres. La mayoría de agresiones ocurren a los médicos (72\%), en los centros asistenciales y saliendo al trabajo/camino al trabajo. Entre los principales tipos de agresión, los encuestados respondieron la agresión verbal, seguida de la discriminación, la violencia física y las amenazas de muerte. En 8.3\% de dichas agresiones hubo necesidad de acompañamiento de la policía, pero solo en $42 \%$ de los casos hubo denuncia respectiva. El 94\% de los encuestados conoce de otras personas del personal de salud que han resultado afectadas.

En Paraguay ha habido comunicados de la SPMI y del Sindicato de Médicos de Guairá (SIMEG) alertando sobre la preocupación por la difusión de los medios de comunicación $(32,33)$ sobre identidad de colegas afectados por el COVID y por el maltrato sufrido por una médica por parte de fuerzas policiales.

Por el contrario, y de manera afortunada, encontramos que otros países como Cuba, Guatemala, República Dominicana y Uruguay no han reportado mayores casos de agresiones o discriminación en contra del personal de salud.

\section{Sobre el ataque físico}

Incluso desde antes del brote, las constantes limitantes de los sistemas de salud han originado una sensación de frustración y malestar en la comunidad, que viene adoptando actitudes desafiantes y poco cordiales hacia el personal de la salud. A su vez, el personal de salud también llega a esta pandemia frustrado por las limitaciones de los sistemas sanitarios, con altas tasas de desgaste (burn-out), con sentimientos de impotencia ante horarios exigentes, pagos retrasados, inestabilidad e informalidad laboral, y faltas de garantías y de beneficios sociales por ley $(28,34)$. Todo lo anterior predispone a un estado de extrema tensión que propicia malos tratos y dificulta los canales de comunicación durante la atención de pacientes. Se han reportado casos de enfrentamientos físicos especialmente de acompañantes o familiares, con tratos impropios hacia el personal de salud. Un meta-análisis en China demostró que la violencia en el lugar de trabajo contra personal de la salud alcanzó valores tan altos hasta de $62 \%$ (5).

Los familiares o acompañantes a menudo concentran los sentimientos de frustración y culpa hacia los miembros del equipo de salud y los requerimientos de aislamiento estricto por la pandemia han incrementado las quejas y la desconfianza hacia los hospitales. En otros lugares, la frustración también resulta de la obligación de separar a pacientes de sus familiares, quienes quedan enfrentados al dilema de no poder ver más a sus seres queridos hasta que estos se hayan recuperado, o desafortunadamente, hasta que hayan fallecido, en cuyo caso las obras fúnebres estarán igualmente limitadas. En Colombia, hubo frecuentes enfrentamientos con los familiares de pacientes fallecidos quienes, al ser informados sobre las medidas de disposición de cadáveres, se rehusaban a aceptar el protocolo de notificación y la sugerencia internacional de cremación. Este comportamiento llegó a tal punto en que la población general empezó a dudar de los reportes médicos, influidos por prensas amarillistas, de quienes surgió la falsa creencia que catalogar como casos de COVID-19 a pacientes sin la enfermedad, estaría generando 
beneficios personales o económicos al personal de salud o los centros hospitalarios, cuando todo lo contrario, los costos en la atención, imagenología y consecución de equipos de protección, han generado sobrecostos y grandes pérdidas para las instituciones sanitarias.

Precisamente, los hechos delictivos más recientes han obedecido a agresiones de familiares contra las plantas físicas de centros de salud cuando se les ha notificado del fallecimiento de un familiar. A pesar de que el cuerpo médico ha expresado toda su voluntad para afrontar esta batalla, sin culpa alguna de la aparición del brote, familiares de pacientes siguen interpretándolos como responsables de los casos mortales, lo cual ha llevado a amenazas de muerte o de demandas argumentando errores médicos o mala praxis, generando comentarios descalificativos que pueden comprometer la reputación del profesional y derrumbar sus esfuerzos y su espíritu. En el peor de los casos, este rencor de personas que responsabilizan al equipo de salud sobre la muerte de sus familiares, ha llegado al punto de considerar el desempeño en el hospital como flagrancia de asesinato en contra de sus familiares; claramente una actitud de terror floreciente en la mentes limitadas y tuertas, carentes de claridad pero de una peligrosidad indefinida y atemorizante ante el riesgo tangente de agresión intra y extramuros.

Otras actitudes agresivas se relacionan con el comportamiento inapropiado de los propios pacientes quienes, a pesar de ser conscientes de la necesidad de reclusión para evitar contagiar a otras personas, rehúsan cooperar con las medidas hospitalarias y se enfrentan directamente con el personal tratante poniendo en riesgo su integridad física. Adicionalmente, se han reportado casos de profesionales de salud o personal administrativo quienes durante su movilización hacia los centros de salud, han sido increpados o interceptados por personas que les han generado agresiones físicas y verbales (34-37). La OMS lamentó la muerte de uno de sus trabajadores en Myanmar cuando fue atacado mientras transportaba muestras de coronavirus en un vehículo (38).

\section{De políticas de personal en formación}

Los sistemas de salud a nivel mundial probablemente operarán a máxima capacidad por muchos meses. Sin embargo, a diferencia de los equipos de ventilación mecánica, que pueden ser manufacturados o comprados, el personal de salud no puede comprarse o trabajar a máxima capacidad por largos períodos (3). Además, la posibilidad que el equipo en salud activo se infecte y tenga que hospitalizarse, irse de baja o en el peor de los casos, fallezca, ha conducido a que servicios sanitarios queden progresivamente recortados de personal.

La respuesta a esta situación ha sido la convocatoria del personal que usualmente no labora en salas de emergencias (subespecialistas, residentes de otros campos) y a la improvisada graduación de estudiantes en último año de carreras afines a la salud (39), para que afronten como soldados rasos la atención de pacientes complicados que se ciñen a protocolos de atención que a menudo fluctúan demasiado rápido, con base a las pocas evidencias disponibles. Esta medida desesperada puede tener sentido en lugares con colapso completo del sistema sanitario, pero en escenarios que no han alcanzado puntos críticos implica enlistar personal no entrenado a una situación de alto riesgo de contagio y con frecuentes quejas por falta de equipo de protección. Algunas instituciones han rediseñado sus programas académicos de formación orientando al personal estudiantil a la atención de servicios "no COVID" o a la realización de actividades que no tienen contacto directo con la atención de enfermos, como el manejo de call-centers o a los seguimientos por tele consulta a pacientes que por síntomas leves son derivados a vigilancia en casa. En otras instituciones, los convenios de docencia retiraron de manera indefinida a sus estudiantes, quienes desarrollan ahora segmentos curriculares a través de reuniones virtuales o desarrollan actividades investigativas, sin conocer aún cual será el impacto sobre la calidad de formación profesional de esta modalidad.

En Colombia, hay al menos nueve casos confirmados de estudiantes del personal de salud que han resultado afectados por la enfermedad (6). Es fundamental que la continuidad de las prácticas o rotaciones hospitalarias vaya de la mano con una coordinación precavida y bajo la absoluta garantía de las medidas de bioseguridad que como profesionales en formación merecen.

\section{Reflexión final y solicitud}

Con base en lo mencionado, se percibe la necesidad en todo nuestro continente de seguir reforzando las tareas de difusión de cara a prevenir y erradicar los casos de discriminación, estigmatización y/o violencia que se presentaron en el periodo considerado, muchos de los cuales tuvieron la particularidad de referirse a situaciones propias del contexto excepcional que nos ha planteado la pandemia. En efecto, se nos presenta un nuevo escenario, con múltiples desafíos, donde se agravan situaciones preexistentes y aparecen otras nuevas, ligadas al momento histórico que atraviesa el mundo, y que obligan a pensar en nuevos abordajes y estrategias para llegar a la mayor cantidad de personas posible.

Por estos motivos, nosotros, especialistas del área clínica de todas las latitudes de Latinoamérica, hacemos un llamado a garantías en esta lucha sin cuartel, que está por comenzar en su más férrea presentación, mediante las siguientes solicitudes y recomendaciones, extensivas también a organizaciones de derechos humanos, organizaciones gubernamentales, a la organización internacional del trabajo y demás autoridades con compromiso multinacional:

1. Que se garantice el aporte de insumos en todos los centros hospitalarios o lugares de atención para los pacientes.

2. Que se garantice al médico con un seguro la educación de sus hijos, la subsistencia de su familia si llega a morir. Pago íntegro de su sueldo a la familia, seguridad social hasta la mayoría de edad de sus hijos, educación gratuita hasta la universidad y seguridad social de por vida para el cónyugue. 
3. Que ante la agresión en persona o bienes del médico y personal de salud se garantice la reparación del daño y la indemnización correspondiente si se discapacita al médico para ejercer su profesión con activación del seguro para su familia.

4. Que las remuneraciones sean acorde con el riesgo y trabajo que se desempeña, para que el médico pueda laborar en una sola institución sin verse obligado a doblar o triplicar las jornadas.

5. Que se respete la reputación del médico, que cuando sea dañada sin justificación sin importar de quien se trate se obligue a la reparación del daño a la imagen profesional y prestigio.

6. Que se prohíba filmar al médico durante su trabajo, publicar su imagen en redes sin su autorización, que esto sea considerado ilegal, que tenga repercusiones para el agresor y se castigue de manera obligando al agresor a la reparación del daño de manera económica y moral.

7. Que las jornadas de trabajo en etapas de entrenamiento sean las estipuladas por la ley, sin pretexto de que por ser personal en entrenamiento se les extienda la jornada sin justificación, y si es así, se les remunere de acuerdo con el tiempo laborado.

8. Que se privilegie el transporte en todas sus versiones para facilitar el desplazamiento de los médicos y personal relacionado con la salud.

9. Que se respete la condición de mujer y sus periodos particulares como el embarazo, la lactancia y la enfermedad de los hijos.

10. Que exista una oficina encargada de los asuntos en particular del médico y personal relacionado con la salud, que agilice y active los mecanismos para ejercer la ley, castigar los delitos y garantizar al médico los rubros antes mencionados, que se ejerza la ley de cada nación en toda su amplitud y rigor, y que con este esfuerzo se logren erradicar vicios que agredan el ejercicio profesional del médico en estas difíciles circunstancias.

El Foro Internacional de Medicina Interna (FIMI) ha elaborado el decálogo sobre las condiciones en las que todo médico debe ejecutar su ejercicio profesional (Anexo 2).

A su vez, se transcribe el mensaje de las autoridades del FIMI para todos los colegas latinoamericanos (Anexo 3).

\section{Referencias}

1. WHO - Organización Mundial de la Salud. Coronavirus disease 2019 (COVID-19) Situation Report - 97. Junio. 2020. Disponible en: https://www.who.int/docs/ default-source/coronaviruse/situation-reports/20200621-covid-19-sitrep-153. pdf?sfvrsn=c896464d 2

2. Chen W, Huang Y. To Protect Healthcare Workers Better, To Save More Lives. Anesth Analg. 2020. Disponible en: https://www.ncbi.nlm.nih.gov/pmc/articles/ PMC7172566/

3. The Lancet. COVID-19: protecting health-care workers. Lancet. 2020;395(10228):922. Disponible en: https://www.ncbi.nlm.nih.gov/pmc/articles/PMC7138074/

4. Zhu J. Is it ethical to be a 'whistleblower' during COVID-19 pandemic? Ethical challenges confronted by health care workers in China. J Adv Nurs. 2020. Disponible en: https://onlinelibrary.wiley.com/doi/full/10.1111/jan.14376

5. Xiang Y, Jin Y, Wang Y, Zhang Q, Zhang L, Cheung T. Tribute to health workers in China: A group of respectable population during the outbreak of the
COVID-19. Int J Biol Sci. 2020;16(10):1739-1740. Disponible en: https://www. ncbi.nlm.nih.gov/pmc/articles/pmid/32226292/

6. Instituto Nacional de Salud [Colombia]. Datos abiertos de COVID-19 en personal de salud, boletín n.8. Junio 2020. Disponible en: https://infogram.com /1pyg0lgpndvwweh3yxlexq1dq1uy617xmpg; https://twitter.com/INSColombia/ status/1273783917061996545/photo/1

7. Redacción Bogotá. (14/04/2020). Anuncian cierre temporal de la UCI del Centro Policlínico del Olaya por brote de COVID-19. El Espectador. Disponible en: https://www.elespectador.com/noticias/bogota/anuncian-cierre-temporal-de-lauci-del-centro-policlinico-del-olaya-por-brote-de-covid-19-articulo-914570

8. Múnera A. (17/04/2020). Cierran servicios en clínica de Pereira por aumento de casos covid-19. El Tiempo. Disponible en: https://www.eltiempo.com/colombia/ en-pereira-cierran-una-clinica-por-propagacion-del-covid-19-485882

9. Urieles R. (23/04/2020). Cierran urgencias en clínica de Santa Marta por incumplir protocolos. El Tiempo. Disponible en: https://www.eltiempo.com/colombia/otrasciudades/coronavirus-en-colombia-cierran-cinica-en-santa-marta-por-incumplirprotocolos-del-coronavirus-487792

10. Nodal Noticias de America Latina y el Caribe. (26.06.2020). Perú se mantiene como el séptimo país con más contagios y ya fallecieron 65 médicos. Disponible en: https://www.nodal.am/2020/06/peru-se-mantiene-como-el-septimo-pais-conmas-contagios-y-ya-fallecieron-65-medicos/

11. Popescu S. Roadblocks to Infection Prevention Efforts in Healthcare SARSCoV-2/COVID-19 Response. Disaster Med Public Health Prep. 2020:1-7. Disponible en: https://www.ncbi.nlm.nih.gov/pmc/articles/PMC7156573/

12. Bong CL, Brasher C, Chikumba E, McDougall R, Mellin-Olsen J, Enright A. The COVID-19 Pandemic: Effects on Low and Middle-Income Countries. Anesth Analg. 2020. Disponible en: https://www.ncbi.nlm.nih.gov/pmc/articles/ PMC7173081/

13. Litewka S, Heitman E. Latin American healthcare systems in times of pandemic. Dev World Bioeth. 2020. Disponible en: https://onlinelibrary.wiley.com/doi/ full/10.1111/dewb.12262

14. Goez A. (08/04/2020). 21 médicos de la Clínica San José de Torices renuncian por falta de insumos. El Universal. Disponible en: https://www.eluniversal.com. co/cartagena/21-medicos-de-la-clinica-san-jose-de-torices-renuncian-por-faltade-insumos-FF2654236

15. López A. (22/04/2020). Terapistas de clínica en Cartagena renuncian por falta de garantías para atender COVID-19 Disponible en: https://www.elheraldo.co/ bolivar/terapistas-de-clinica-en-cartagena-renuncian-por-falta-de-garantias-paraatender-covid-19

16. Redacción Nacional. (22/04/2020). Historia de una médica despedida por solicitar prueba del covid-19. Semana. Disponible en: https://www.semana.com/semanatv/semana-noticias/articulo/coronavirus-en-colombia-despiden-a-medica-porsolicitar-prueba-de-covid--19/665144

17. Hero I. Prevent loss of life by providing all NHS staff with WHO standard personal protective equipment. BMJ 2020;368:m1275. Disponible en: https://www.bmj. com/content $/ 368 /$ bmj.m 1275

18. Redacción Nacional Ecuatoriana. Disponible en: https://www.edicionmedica.ec/ secciones/profesionales/federacion-medica-ecuatoriana-advierte-sobre-variosproblemas-en-el-sistema-de-salud--96045

19. Mo Y, Deng L, Zhang L, Lang Q, Liao C, Wang N, et al. Work stress among Chinese nurses to support Wuhan for fighting against the COVID-19 epidemic. $J$ Nurs Manag. 2020 Disponible en: https://onlinelibrary.wiley.com/doi/abs/10.1111/ jonm.13014

20. Greenberg N, Docherty M, Gnanapragasam S, Wessely S. Managing mental health challenges faced by healthcare workers during covid-19 pandemic. BMJ. 2020;368:m1211. Disponible en: https://www.bmj.com/content/368/bmj.m1211. long

21. Ripp J, Peccoralo L, Charney D. Attending to the Emotional Well-Being of the Health Care Workforce in a New York City Health System During the COVID-19 Pandemic. Acad Med. 2020 Disponible en: https://www.ncbi.nlm.nih.gov/pmc/ articles/PMC7176260/

22. Montemurro N. The emotional impact of COVID-19: From medical staff to common people. Brain Behav Immun. 2020. pii: S0889-1591(20)30411-6. Disponible en: https://www.ncbi.nlm.nih.gov/pmc/articles/pmid/32240766/

23. Chen Q, Liang M, Li Y1, Guo J, Fei D, Wang L, et al. Mental health care for medical staff in China during the COVID-19 outbreak. Lancet Psychiatry. 2020;7(4):e15-e16. Disponible en: https://www.ncbi.nlm.nih.gov/pmc/articles/ $\mathrm{pmid} / 32085839 /$

24. World Health Organization. (2020). Mental health and psychosocial considerations during the COVID-19 outbreak. 2020. World Health Organization. Disponible en: https://apps.who.int/iris/handle/10665/331490

25. López A. (20/04/2020). 84\% de médicos generales de la Costa le temen a la COVID-19. El Heraldo. Disponible en: https://www.elheraldo.co/colombia/envideo-84-de-medicos-generales-de-la-costa-le-temen-la-covid-19-719159 
26. Jaime J. (22/04/2020). El personal de salud no es inmune al miedo. El Espectador. Disponible en: https://www.elespectador.com/coronavirus/el-personal-de-saludno-es-inmune-al-miedo-articulo-916025

27. El País. (23/04/2020). Autoridades investigan amenaza de muerte que recibió un médico en Bogotá. El País. Disponible en: https://www.elpais.com.co/colombia/ autoridades-investigan-amenaza-de-muerte-que-recibio-un-medico-en-bogota. $\underline{\mathrm{html}}$

28. EFE. (01/04/2020). La COVID-19 desata la discriminación en Colombia contra quienes salvan vidas. EFE Disponible en: https://www.efe.com/efe/america/ sociedad/la-covid-19-desata-discriminacion-en-colombia-contra-quienes-salvanvidas/20000013-4211172

29. Nación. (10/04/2020). En defensa de los héroes: los médicos sufren discriminación. Semana. Disponible en: https://www.semana.com/nacion/articulo/discriminaciona-medicos-y-trabajadores-de-la-salud-por-coronavirus/662655

30. Castrillón D. (24/04/2020). Colombia: Defensoría del Pueblo recibirá denuncias de amenazas al personal de la salud. CNN en español. Disponible en: https:// cnnespanol.cnn.com/2020/04/24/alerta-colombia-defensoria-del-pueblo-abreun-canal-para-recibir-denuncias-de-amenazas-al-personal-de-la-salud/

31. Redacción. (08.05.2020). Los Olivos: Hombre escupe en la cara a enfermera en una clínica. Diario El Correo. Disponible en: https://diariocorreo.pe/edicion/lima/ los-olivos-hombre-escupe-a-enfermera-en-una-clinica-coronavirus-peru-covid19-video-noticia/

32. Denuncian posible "caza de brujas" en Villarrica por caso de coronavirus. 12 de abril de 2020. Disponible en: https://www.hoy.com.py/nacionales/denuncianposible-caza-de-brujas-en-villarrica-por-caso-de-coronavirus

33. Escrachan a médicos y los acusan de contagiar COVID-19 en Concepción. 10 de junio de 2020. Disponible en: https://www.lanacion.com.py/pais/2020/06/10/ escrachan-a-medicos-y-los-acusan-de-contagiar-covid-19-en-concepcion/\#. XvOuAwrOdsU.whatsapp

34. González D. (04/04/2020). Entre aplausos y discriminación, la lucha de los médicos contra el Covid-19 en Argentina y Colombia. France 24. Disponible en: https://www.france24.com/es/20200404-discriminacion-medicos-argentinacolombia-coronavirus

35. Redacción nacional. (14/04/2020). Alcaldía de Montería rechazó agresión contra enfermera del hospital San Jerónimo. El Espectador. Disponible en: https://www. elespectador.com/coronavirus/alcaldia-de-monteria-rechazo-agresion-contraenfermera-del-hospital-san-jeronimo-articulo- 914548

36. Redacción nacional. (18/04/2020). Enfermera en Barranquilla fue atacada tras ser acusada de tener covid-19. Semana. Disponible en: https://www.semana.com/ nacion/articulo/coronavirus-en-colombia-agreden-a-enfermera-en-barranquillapor-la-covid-19/664524

37. Agredo P. (16/04/2020). Personal médico en Medellín denuncia que han recibido agresiones físicas. RCN Radio. Disponible en: https://www.renradio.com/ colombia/antioquia/personal-medico-en-medellin-denuncia-que-han-recibidoagresiones-fisicas

38. Sharma S. (21/04/2020). WHO condoles death of staff in Myanmar, condemns targeting of health workers involved in COVID19 response. WHO SEAR/PR. Disponible en: https://www.who.int/southeastasia/news/detail/21-04-2020-whocondoles-death-of-staff-in-myanmar-condemns-targeting-of-health-workersinvolved-in-covid19-response

39. Linde P, Silió E. (19/03/2020) El colapso del sistema obliga a Sanidad a contrata a miles de jubilados y estudiantes. El País. Disponible en: https://elpais.com/sociedad/2020-03-19/espana-suma-169-muertos-y-3431-nuevos-casos-de-coronavirus.html 
Anexo 1. Listado de agresiones identificadas en prensa durante pandemia COVID-19 en Latinoamérica.

\begin{tabular}{|c|c|c|c|c|c|c|}
\hline País & Ciudad / Departamento o Estado & Personal afectado & Sexo & Sitio & Agresión & Fecha (2020) \\
\hline \multirow{10}{*}{ Argentina } & Ciudad de Bs.As./Belgrano & Médicos & M & Vivienda & Amenazas & NR \\
\hline & Ciudad de Bs.As./Villa Crespo & Médicos & M & Vivienda & Amenazas, Agresión verbal & NR \\
\hline & Ciudad de Bs.As. / Recoleta & Enfermería & $\mathrm{F}$ & Vivienda & Agresión verbal & NR \\
\hline & Provincia San Luis & Médicos & M & Centro asistencial & Agresión física & NR \\
\hline & Rosario - Provincia de Santa Fe & Médicos & M & Ambulancia & Agresión mixta & NR \\
\hline & Provincia de La Rioja & Médicos & $\mathrm{F}$ & Vivienda & Destrucción de propiedad & NR \\
\hline & Provincia de Bs.As - Mar del Plata & Médicos & $\mathrm{F}$ & Vivienda & Agresión física & NR \\
\hline & Rosario - Provincia De Santa Fe & Enfermería & $\mathrm{F}$ & Centro asistencial & Agresión mixta & NR \\
\hline & Provincia de Bs.As - La Plata & Médicos & M & Consultorio & Amenazas & NR \\
\hline & Provincia de Santa Fé -Venado Tuerto & Médicos & M & Centro asistencial & Agresión verbal & NR \\
\hline \multirow{12}{*}{ Bolivia } & Cochabamba & Equipo de salud & $\mathrm{NA} / \mathrm{NE}$ & Centro asistencial & Amenazas & junio \\
\hline & Cochabamba & Médicos & $\mathrm{F}$ & Vivienda & Discriminación & junio \\
\hline & Cochabamba & Médicos & M & Centro asistencial & Agresión mixta & junio \\
\hline & $\mathrm{LaPaz}$ & Equipo de salud & $\mathrm{NA} / \mathrm{NE}$ & Centro asistencial & Amenazas & mayo \\
\hline & El Alto & Médicos & $\mathrm{NA} / \mathrm{NE}$ & Espacio público & Agresión física & mayo \\
\hline & $\mathrm{LaPaz}$ & Médicos & NA/NE & Hotel de aislamiento & Discriminación & junio \\
\hline & Oruro & Médicos & NA/NE & Centro asistencial & Agresión mixta & junio \\
\hline & Yapacaní / Santa Cruz & Médicos & $\mathrm{NA} / \mathrm{NE}$ & Espacio público & Amenazas & junio \\
\hline & Cochabamba & Médicos & NA/NE & Espacio público & Amenazas & junio \\
\hline & Cochabamba & Médicos & $\mathrm{F}$ & Vivienda & Discriminación & abril \\
\hline & Beni & Equipo de salud & $\mathrm{NA} / \mathrm{NE}$ & Centro asistencial & Amenazas & abril \\
\hline & El Alto & Paramédicos & $\mathrm{NA} / \mathrm{NE}$ & Espacio público & Agresión física & mayo \\
\hline \multirow{20}{*}{ Colombia } & Barranquilla / Atlántico & Enfermería & $\mathrm{F}$ & Espacio público & Agresión mixta & abril \\
\hline & Bogotá (D.Capital) & Médicos & M & Vivienda & Amenazas & abril \\
\hline & Bogotá (D.Capital) & Enfermería & $\mathrm{F}$ & Espacio público & Agresión mixta & mayo \\
\hline & Bogotá (D.Capital) & Equipo de salud & $\mathrm{F}$ & Vivienda & Discriminación & mayo \\
\hline & Cali / Valle & Equipo de salud & $\mathrm{NA} / \mathrm{NE}$ & NA/NE & Agresión mixta & abril \\
\hline & Cali / Valle & Médicos & $\mathrm{F}$ & Comercio & Discriminación & abril \\
\hline & Cali / Valle & Médicos & M & Vivienda & Discriminación & abril \\
\hline & Cartagena / Bolívar & Equipo de salud & $\mathrm{NA} / \mathrm{NE}$ & Transporte público & Discriminación & abril \\
\hline & Cartagena / Bolívar & Médicos & $\mathrm{NA} / \mathrm{NE}$ & Centro asistencial & Agresión mixta & junio \\
\hline & Cartagena / Bolívar & Médicos & M & Centro asistencial & Agresión mixta & junio \\
\hline & Medellín / Antioquia & Enfermería & NA/NE & Vivienda & Discriminación & abril \\
\hline & Medellín / Antioquia & $\begin{array}{l}\text { Tecnóloga en atención } \\
\text { prehospitalaria }\end{array}$ & $\mathrm{F}$ & Espacio público & Agresión física & abril \\
\hline & Montería / Córdoba & Enfermería & $\mathrm{F}$ & Espacio público & Agresión mixta & abril \\
\hline & Montería / Córdoba & Enfermería & $\mathrm{F}$ & Vivienda & Discriminación & abril \\
\hline & Montería / Córdoba & Médicos & M & Vivienda & Discriminación & abril \\
\hline & Montería / Córdoba & Equipo de salud & $\mathrm{NA} / \mathrm{NE}$ & Centro asistencial & Destrucción de inmueble & junio \\
\hline & Soledad / Atlántico & Equipo de salud & NA/NE & Centro asistencial & Agresión física & mayo \\
\hline & Soledad / Atlántico & Médicos & M & Vivienda & Amenazas & junio \\
\hline & Tolima & Enfermería & $\mathrm{F}$ & Comercio & Discriminación & abril \\
\hline & Valledupar / Cesar & Trabajadora social & $\mathrm{F}$ & Vivienda & Discriminación & abril \\
\hline Costa Rica & Alajuela & Enfermería & $\mathrm{NA} / \mathrm{NE}$ & Transporte Público & Discriminación & marzo \\
\hline Cuba & - & - & - & - & No reportan agresiones & - \\
\hline
\end{tabular}


Continuación. Anexo 1. Listado de agresiones identificadas en prensa durante pandemia COVID-19 en Latinoamérica.

\begin{tabular}{|c|c|c|c|c|c|c|}
\hline País & Ciudad / Departamento o Estado & Personal afectado & Sexo & Sitio & Agresión & Fecha $(2020)$ \\
\hline El Salvador & San Salvador & Enfermería & NA/NE & Vivienda & Discriminación & abril \\
\hline Guatemala & - & - & - & - & No reportan agresiones & - \\
\hline \multirow{4}{*}{ Honduras } & $\mathrm{NE}$ & Enfermería & $\mathrm{F}$ & Vivienda & Discriminación & abril \\
\hline & Cortés & Enfermería & $\mathrm{F}$ & Vivienda & Discriminación & mayo \\
\hline & San Pedro Sula & Enfermería & $\mathrm{F}$ & Vivienda & Discriminación & mayo \\
\hline & San Pedro Sula & Enfermería & $\mathrm{F}$ & Vivienda & Discriminación & junio \\
\hline \multirow{40}{*}{ México } & Bahía de Banderas, Nayarit & Enfermería & $\mathrm{F}$ & Vivienda & Discriminación & abril \\
\hline & Balbuena, CDMX & Médicos & M & Transporte Público & Discriminación & abril \\
\hline & Cadereyta, Querétaro & Enfermería & $\mathrm{F}$ & Espacio público & Agresión física & abril \\
\hline & Chiapas & Equipo de salud & $\mathrm{NA} / \mathrm{NE}$ & Centro asistencial & Destrucción de inmueble & mayo \\
\hline & CDMX & Enfermería & $\mathrm{F}$ & Transporte Público & Agresión verbal & abril \\
\hline & CDMX / Azcapotzalco & Enfermería & M & Centro asistencial & Agresión física & abril \\
\hline & CDMX / Azcapotzalco & Médicos & $\mathrm{F}$ & Centro asistencial & Amenazas & abril \\
\hline & Ciudad de México & Enfermería & $\mathrm{F}$ & Espacio público & Discriminación & abril \\
\hline & Ciudad de México & Enfermería & $\mathrm{F}$ & Espacio público & Discriminación & abril \\
\hline & Ciudad de México & Enfermería & F & Espacio público & Agresión física & abril \\
\hline & Ciudad de México & Enfermería & $\mathrm{F}$ & Comercio & Discriminación & abril \\
\hline & Ciudad de México & Médicos & NA/NE & Centro asistencial & Amenazas & abril \\
\hline & Ciudad de México & Enfermería & $\mathrm{F}$ & No registrado & Agresión física & abril \\
\hline & Ciudad Obregón, Sonora & Enfermería & $\mathrm{F}$ & Espacio público & Agresión Física & abril \\
\hline & Córdoba, Veracruz & Enfermería & $\mathrm{F}$ & Transporte Público & Discriminación & abril \\
\hline & Culiacán & Enfermería & $\mathrm{F}$ & Espacio público & Agresión física & abril \\
\hline & Ecatepec, Edo Mex & Enfermería & $\mathrm{F}$ & Espacio público & Agresión por autoridades & mayo \\
\hline & Estado de México & Enfermería & $\mathrm{F}$ & Transporte Público & Agresión física & abril \\
\hline & Estado de México & Enfermería & M & Transporte Público & Discriminación & abril \\
\hline & Guadalajara, Jalisco & Médicos & $\mathrm{F}$ & Espacio público & Agresión Física & abril \\
\hline & Guadalajara, Jalisco & Paramédicos & M & Espacio público & Agresión Física & abril \\
\hline & Jalisco & Enfermería & $\mathrm{F}$ & Centro asistencial & Agresión mixta & abril \\
\hline & Jalisco & Enfermería & $\mathrm{F}$ & Espacio público & Agresión mixta & abril \\
\hline & Las Margaritas, Chiapas & Médicos & M & Centro asistencial & Agresión física & junio \\
\hline & Mérida, Yucatán & Enfermería & M & Transporte Público & Agresión física & abril \\
\hline & Mérida, Yucatán & Enfermería & $\mathrm{F}$ & Espacio público & Agresión física & abril \\
\hline & Mérida, Yucatán & Enfermería & $\mathrm{F}$ & Vivienda & Destrucción de inmueble & mayo \\
\hline & Monclova, Coahuila & Médicos & M & Vehículo personal & Agresión por autoridades & abril \\
\hline & Morelos & Equipo de salud & $\mathrm{NA} / \mathrm{NE}$ & Centro asistencial & Amenazas & abril \\
\hline & Oaxaca & Enfermería & M & Comercio & Discriminación & abril \\
\hline & Oaxaca & Equipo de salud & NA/NE & Centro asistencial & Agresión física & abril \\
\hline & Oblatos, Jalisco & Enfermería & $\mathrm{F}$ & Transporte Público & Agresión mixta & marzo \\
\hline & Querétaro & Enfermería & F & Transporte Público & Agresión mixta & abril \\
\hline & Reynosa, Tamaulipas & Enfermería & M & Espacio público & Agresión física & abril \\
\hline & San Luis Potosí & No especificado & $\mathrm{F}$ & Comercio & Agresión física & abril \\
\hline & San Melchor & Paramédicos & $\mathrm{NA} / \mathrm{NE}$ & Ambulancia & Agresión física & mayo \\
\hline & Sonora & Enfermería & M & Vivienda & Discriminación & abril \\
\hline & Tamaulipas & Enfermería & $\mathrm{NA} / \mathrm{NE}$ & Espacio público & Secuestro & mayo \\
\hline & Tampico & Técnico en Urgencias & M & Transporte Público & Discriminación & abril \\
\hline & Veracruz & Enfermería & NA/NE & Comercio & Discriminación & abril \\
\hline
\end{tabular}


EDUCACIÓN Y PRÁCTICA DE LA MEDICINA • Ataque al personal de la salud en Latinoamérica

Continuación. Anexo 1. Listado de agresiones identificadas en prensa durante pandemia COVID-19 en Latinoamérica.

\begin{tabular}{|c|c|c|c|c|c|c|}
\hline País & Ciudad / Departamento o Estado & Personal afectado & Sexo & Sitio & Agresión & Fecha $(2020)$ \\
\hline \multirow{4}{*}{ Panamá } & Comunicado nacional & Equipo de salud & $\mathrm{NA} / \mathrm{NE}$ & Centro asistencial & Amenazas & junio \\
\hline & Veraguas & Médicos & $\mathrm{NA} / \mathrm{NE}$ & Vivienda & Discriminación & abril \\
\hline & No especificado & Médicos & $\mathrm{F}$ & Vivienda & Discriminación & abril \\
\hline & No especificado & Enfermería & $\mathrm{F}$ & Transporte público & Discriminación & abril \\
\hline \multirow{8}{*}{ Paraguay } & Asunción & Médicos & $\mathrm{F}$ & Redes sociales & Discriminación & marzo \\
\hline & Asunción & Médicos & $\mathrm{F}$ & Redes sociales & Discriminación & marzo \\
\hline & $\mathrm{CDE}$ & Terapista & $\mathrm{F}$ & Redes sociales & Agresión verbal & marzo \\
\hline & $\mathrm{CDE}$ & Médicos & M & Redes sociales & Agresión verbal & marzo \\
\hline & Guaira & Médicos & $\mathrm{F}$ & Vivienda & Agresión verbal & abril \\
\hline & Guaira & Enfermería & $\mathrm{F}$ & Vivienda & Discriminación & abril \\
\hline & Concepción & Médicos & M & Centro asistencial & Agresión verbal & junio \\
\hline & Altos & Enfermería & $\mathrm{F}$ & Vivienda & Agresión verbal & abril \\
\hline \multirow{3}{*}{ Perú } & Lima / San Juan de Lurigancho & Equipo de Salud & NA/NE & Centro asistencial & Agresión física & abril \\
\hline & Piura / Talara & Médicos & $\mathrm{NA} / \mathrm{NE}$ & Centro asistencial & Agresión física & mayo \\
\hline & Lima / Los Olivos & Enfermera & $\mathrm{F}$ & Centro Asistencial & Agresión física & mayo \\
\hline República Dominicana & - & - & - & - & No reportan agresiones & - \\
\hline Uruguay & - & - & - & - & No reportan agresiones & - \\
\hline \multirow{9}{*}{ Venezuela } & Carora /Lara & Médicos & M & Consultorio & Agresión por autoridades & abril \\
\hline & Margarita/Nueva Esparta & Médicos & $\mathrm{F}$ & $\mathrm{NA} / \mathrm{NE}$ & Agresión por autoridades & abril \\
\hline & Villa de Cura/Aragua & Médicos & M & Espacio público & Agresión por autoridades & $\mathrm{NA} / \mathrm{NE}$ \\
\hline & San Cristóbal/Táchira & Enfermería & M & Centro asistencial & Agresión por autoridades & NA / NE \\
\hline & Maturín/Monagas & Médicos & M & Centro asistencial & Agresión por autoridades & $\mathrm{NA} / \mathrm{NE}$ \\
\hline & Maturín/Monagas & Médicos & M & Centro asistencial & Agresión por autoridades & $\mathrm{NA} / \mathrm{NE}$ \\
\hline & Maturín/Monagas & Médicos & $\mathrm{F}$ & Centro asistencial & Agresión por autoridades & NA / NE \\
\hline & Barquisimeto/Lara & Médicos & M & Centro asistencial & Agresión por autoridades & junio \\
\hline & Zaraza/Guárico & Médicos & M & Centro asistencial & Agresión por autoridades & junio \\
\hline
\end{tabular}


Anexo 2. Decálogo sobre las condiciones en las que todo médico debe ejecutar su ejercicio profesional.

1. Ejercer la profesión en forma libre y sin presiones de cualquier naturaleza. El médico tiene derecho a que se respete su juicio clínico (diagnóstico y terapéutico) y su libertad prescriptiva, así como su probable decisión de declinar la atención de algún paciente, siempre que tales aspectos se sustenten sobre bases éticas, científicas y normativas.

2. Laborar en instalaciones apropiadas y seguras que garanticen su práctica profesional. El médico tiene derecho a contar con lugares de trabajo e instalaciones que cumplan con medidas de seguridad e higiene, incluidas las que marca la ley, de conformidad con las características del servicio a otorgar.

3. Tener a su disposición los recursos que requiere su práctica profesional. Es un derecho del médico, recibir del establecimiento donde presta sus servicios: personal idóneo, así como equipo, instrumentos e insumos necesarios, de acuerdo con el servicio que otorgue.

4. Abstenerse de garantizar resultados en la atención médica. El médico tiene derecho a no emitir juicios concluyentes sobre los resultados esperados de la atención médica.

5. Recibir trato respetuoso por parte de los pacientes y sus familiares, así como del personal relacionado con su trabajo profesional. El médico tiene derecho a recibir del paciente y sus familiares trato respetuoso, así como información completa, veraz y oportuna relacionada con el estado de salud. El mismo respeto deberá recibir de sus superiores, personal relacionado con su trabajo profesional y terceros pagadores.

6. Tener acceso a educación médica continua y ser considerado en igualdad de oportunidades para su desarrollo profesional. El médico tiene derecho a que se le facilite el acceso a la educación médica continua y a ser considerado en igualdad de oportunidades para su desarrollo profesional, con el propósito de mantenerse actualizado.

7. Tener acceso a actividades de investigación y docencia en el campo de su profesión. El médico tiene derecho a participar en actividades de investigación y enseñanza como parte de su desarrollo profesional.

8. Asociarse para promover sus intereses profesionales. El médico tiene derecho a asociarse en organizaciones, asociaciones y colegios para su desarrollo profesional, con el fin de promover la superación de sus miembros y vigilar el ejercicio profesional, de conformidad con lo prescrito en la ley.

9. Salvaguardar su prestigio profesional. El médico tiene derecho a la defensa de su prestigio profesional y a que la información sobre el curso de una probable controversia se trate con privacidad, y en su caso a pretender el resarcimiento del daño causado. La salvaguarda de su prestigio profesional demanda de los medios de comunicación respeto al principio de legalidad y a la garantía de audiencia, de tal forma que no se presuma la comisión de ilícitos hasta en tanto no se resuelva legalmente cualquier controversia por la atención médica brindada.

10. Percibir remuneración por los servicios prestados. El médico tiene derecho a ser remunerado por los servicios profesionales que preste, de acuerdo a su condición laboral, contractual o a lo pactado con el paciente. 
Anexo 3. Mensaje de las autoridades del FIMI para los colegas de Latinoamérica.

Colegas del FIMI:

Nos encontramos todos trabajando, cada uno en lo suyo y siempre desde la medicina interna, ya sea en la atención comunitaria, ambulatoria, en la sala de guardia, en la ambulancia, en la sala de internación general o en cuidados progresivos, en la atención domiciliaria, y ahora haciendo triage en los distintos puntos de nuestros países.

Otros están gestionando hospitales, salas de internación, elaborando tácticas de triage, escribiendo documentos y además, como somos referentes de muchos pacientes o de conocidos, e incluso de miembros del equipo de salud, a veces con los celulares a full respondiendo consultas y asesorando.

Les queremos decir que a esta pandemia la vamos a combatir con todo el arsenal que tenemos: de conocimientos, de debate (entre los clínicos y con el resto del equipo de salud, ya sea a nivel societario o institucional), de poner el hombro, de pensar, y fundamentalmente con una de las herramientas más poderosas: la solidaridad.

La cuarentena y el trabajo asistencial y de gestión de instituciones al que nos vemos sometidos en el último período nos plantea un desafío que los clínicos vamos a saber enfrentar porque casi todos y casi siempre apelamos a la resiliencia y mal no nos ha resultado. Somos un continente de clínicos unidos a través del FIMI, sus sociedades, y a algunos nos están escuchando, junto a otros colegas, en algunos ministerios de salud.

Vinieron, están y vendrán tiempos difíciles y la dificultad será diferente según el contexto geográfico y laboral, somos conscientes, pero le daremos pelea con la voluntad que tenemos (aunque lógicamente a veces oscila) y con las competencias que nos caracterizan, y que sabemos exponer en tiempos de crisis.

No aceptaremos:

$\checkmark$ Que nos hagan trabajar sin los Equipos de Protección Personal adecuados a cada caso.

$\checkmark$ La judicialización apresurada que está ocurriendo en muchas regiones, producto del miedo y de la necesidad de culpar a alguien.

$\checkmark$ La agresión (siempre COBARDE) ejercida por algunos sectores de la ciudadanía, en ninguna de sus máscaras: física, psíquica, social, discriminatoria.

$\checkmark$ El relegamiento a un segundo plano respecto a otras especialidades, ya sea por el público, por la prensa, por los dirigentes, por la ciudadanía, por otros colegas. Los clínicos / internistas somos los que ponemos el pecho al virus.

$\checkmark$ La intolerancia hacia otros colegas (de la misma u otra nación).

\author{
Salgo a caminar \\ por la cintura cósmica del sur. \\ Piso en la región \\ más vegetal del viento y de la luz. \\ Siento al caminar \\ toda la piel de América en mi piel \\ y anda en mi sangre un río \\ que libera en mi voz su caudal.
}

